\title{
A DENUNCIAÇÃO DA LIDE NAS AÇÕES INDENIZATÓRIAS CONTRA MÉDICOS
}

\author{
THE THIRD-PARTY COMPLAINT IN ACTION FOR DAMAGES AGAINST PHYSICIANS
}

\author{
Roberto Augusto de Carvalho Campos ${ }^{1}$ \\ Fabricio Ferrari Butti ${ }^{2}$ \\ Rosmari Aparecida Elias Camargo ${ }^{3}$
}

\begin{abstract}
Resumo:
A utilização do instituto da denunciação da lide nas ações indenizatórias, nas quais se discute a responsabilidade dos prestadores de serviços médicos, não raro é feita de forma inadequada e desvirtuada de seus princípios e natureza jurídica.

Ao ingressar em uma demanda em curso, previamente estabelecida entre consumidor e pessoa jurídica prestadora de serviços médicos, o médico litisdenunciado se defrontará com duas discussões distintas, quais sejam, eventuais vícios acerca do serviço médico, objeto da demanda originária, e também a natureza da relação jurídica havida com o denunciante.

O estabelecimento de argumentações dessa natureza pode se tornar prejudicial aos interesses do autor da demanda, além de afrontar vedação expressa contida na legislação consumerista.

A análise de decisões proferidas em Tribunais pátrios direciona para o entendimento da inaplicabilidade do instituto da denunciação da lide em ações fundadas na responsabilidade civil por prestação de serviços médicos.
\end{abstract}

Palavras-chave: Denunciação da lide. Erro médico. Responsabilidade civil. Ação indenizatória. Intervenção de terceiros.

\begin{abstract}
:
It is not at all rare that the use of the established laws of third-party complaint in action for damages, where the accountability on services rendered by physicians is discussed is carried out inadequately and misinterpreted in its principles and legal nature.

When joining an ongoing litigation that was previously established between the consumer and the legal entity rendering medical services, the physician while impleaded party will face two different discussions, i.e., fortuitous vices concerning the medical service, that is being discussed in the original suit, and also the nature of the legal relationship with the accuser .

The presentation of allegations of such nature may jeopardize the interests of the pleader, and confront the inherent prohibition contained in the legislation on consumers.
\end{abstract}

1 Professor Doutor do Departamento de Direito Penal, Medicina Forense e Criminologia da Faculdade de Direito da Universidade de São Paulo. http://www.camargoecampos.com.br.

2 Advogado em São Paulo, convidado do Autor supracitado.

3 Mestre em Direito Penal pela Faculdade de Direito da Universidade de São Paulo, convidada do Autor citado na nota $n .1$. 
The analysis of decisions pronounced in the Courts leads to an understanding of the irrelevance of the established laws of third party complaint in action for damages based on civil accountability while rendering medical services.

Keywords: Third-party complaint in action for damages. Medical error. Civil accountability. Action for damages. Intervention of third parties.

\section{Introdução}

Em se tratando de ações indenizatórias fundadas em responsabilidade civil por ato médico, a intervenção de terceiros, visando a ampliação do pólo passivo da demanda, vem sendo largamente utilizada pelos litigantes, em muitos casos na forma de denunciação da lide.

Em sua modalidade não-obrigatória, prevista no art. 70, III, do Código de Processo Civil brasileiro, a denunciação da lide tem sido objeto de controvérsias jurídicas, sendo perceptível, inclusive, um desvirtuamento de seus objetivos e da própria natureza jurídica nos casos que envolvem prestação de serviços médicos, situações em que a denunciação é utilizada na expectativa de transferir responsabilidade pelo evento danoso.

$\mathrm{O}$ instituto da denunciação da lide surgiu em nosso ordenamento jurídico com a denominação de chamado à autoria, instituído pelo Regulamento n. 737 , de 25/11/1850. Passou a receber a denominação de denunciação da lide a partir do Código de Processo Civil, aprovado em janeiro de 1973, que entrou em vigor no ano seguinte, fruto do anteprojeto elaborado por Alfredo Buzaid.

O nosso ordenamento jurídico, acompanhando os demais países latinos, assimilou o conceito primitivo germânico de denunciação da lide - advocatio warrantum, consistente na obrigação do garante de assumir a posição do garantido no processo.

A origem do instituto no Direito Romano - denunciatio litis - era aplicada nas hipóteses de evicção, nas vendas realizadas pela traditio e, ainda, nas situações em que o fidejussor prometia pagar o débito de outra pessoa. $\mathrm{O}$ denunciado não era obrigado a intervir no processo, funcionando a denunciação como uma notificação acerca da existência do litígio. No entanto, era obrigatória para o denunciante, sob pena de perda do direito de regresso.

Sua natureza jurídica está relacionada à noção de garantia, tanto que na França e na Itália a denunciação da lide recebeu o nome chamamento em garantia (chiamata in garanzia). ${ }^{4}$

\footnotetext{
${ }_{4}$ GONÇALVES, Aroldo Plínio. Da denunciação da lide. Rio de Janeiro: Editora Forense, 1998.
} 
Em sua evolução histórica observa-se que "o instituto se ampliou, da hipótese de evicção, para todos os casos de garantia, eliminando-se também a penalidade da perda do direito de regresso pela falta de denunciação", conforme sintetiza Greco Filho. ${ }^{5}$

Justamente essa posição de garante que permeia a relação entre denunciante e denunciado tem motivado o uso do instituto em situações nas quais é discutível juridicamente o seu cabimento.

Observando as demais modalidades de intervenção de terceiros, mormente aquelas em que o terceiro assume condição de parte, percebe-se que elas também não atendem aos interesses manifestados pelos denunciantes em suas tentativas de imputar aos médicos a responsabilidade pelo fato objeto da demanda.

Da análise doutrinária das outras modalidades de intervenção de terceiros, podemos destacar o chamamento ao processo como a mais próxima aos objetivos daqueles que pretendem trazer um terceiro que deverá ser o responsável pelo resultado da ação principal.

Até mesmo pelo fato de no chamamento ao processo haver uma relação entre autor e chamado, este instituto afigura-se mais adequado a algumas situações em que o objeto da demanda é um ato médico.

No ensinamento de Cheim Jorge, no chamamento ao processo a ação poderia ter sido proposta diretamente em face do chamado, enquanto na denunciação, o denunciado não teria legitimidade ad causam caso a ação fosse proposta diretamente em face dele. ${ }^{6}$

Se o médico denunciado, pela natureza jurídica da relação estabelecida com o autor da ação, poderia ocupar originalmente a posição de réu, tal condição nos reporta imediatamente ao instituto do chamamento ao processo.

No entanto, embora tais características integrem as explicações doutrinárias sobre o instituto, uma interpretação literal do dispositivo legal que define as hipóteses de chamamento ao processo, desperta dúvidas quanto sua utilização nos casos em comento.

Em se tratando a denunciação da lide do exercício antecipado do direito de regresso, sua procedência está condicionada à sucumbência do denunciante na ação

5 GRECO FILHO, Vicente. Direito processual civil brasileiro. 9. ed. atual. São Paulo: Saraiva, 1994. v. 1.

6 CHEIM JORGE, Flávio. Chamamento ao processo. 2. ed. rev. e atual. São Paulo: Revista dos Tribunais, 1999. 
principal, o que enseja uma decisão dupla em uma única sentença, conforme sintetiza Gonçalves. $^{7}$

O diploma processual civil prevê no art. 70 três situações distintas para o cabimento da denunciação da lide. Apesar do caput do artigo adjetivar as situações como obrigatórias, a obrigatoriedade efetiva está contida apenas no inciso primeiro, que se refere ao exercício do direito de evicção pelo adquirente. ${ }^{8}$

$\mathrm{O}$ inciso primeiro do art. 70 trata da obrigação da parte contra quem se reivindica a coisa de denunciar à lide o alienante imediato ou qualquer dos anteriores. Aquele que se omite no exercício da denunciação perde o direito material relativo à indenização. ${ }^{9}$

O inciso seguinte prevê a situação daquele que exerce a posse direta da coisa demandada e é citado em nome próprio, como o usufrutuário, o credor pignoratício ou o locatário, podendo denunciar à lide o proprietário ou possuidor indireto.

O último inciso, este sim que interessa para a situação exposta no presente trabalho, contempla o exercício do direito de regresso, permitindo que seja denunciado à lide aquele que estiver obrigado pela lei ou por contrato a indenizar em futura ação de regresso o prejuízo daquele que perder a demanda.

A demanda paralela que se estabelece entre denunciante e denunciado acaba por trazer novos fatos e fundamentos jurídicos à demanda, o que muitas vezes é prejudicial aos interesses do autor da ação originária; principalmente nas ações interpostas após o advento do Código de Defesa do Consumidor, que permite a responsabilização objetiva dos prestadores de serviços.

O ingresso do médico denunciado nos autos impõe a discussão dos fatos sob a égide dos elementos da culpa, havendo de se perquirir se o facultativo obrou com negligência, imprudência ou imperícia.

Doutrinadores e parte da jurisprudência rechaçam a denunciação da lide sempre que o instituto significar o advento de fundamento jurídico novo nos autos, a exemplo de Greco Filho. ${ }^{10}$

7 GONÇALVES, Aroldo Plínio. Da denunciação da lide. Rio de Janeiro: Editora Forense, 1998.

8 NERY JUNIOR, Nelson; NERY, Rosa Maria de Andrade. Código de processo civil comentado e legislação extravagante: atualizado até 01 de março de 2006. 9. ed. rev., atual. e ampl. São Paulo: Revista dos Tribunais, 2006.

9 WAMBIER, Luiz Rodrigues (Coord.). Curso avançado de processo civil: teoria geral do processo e processo de conhecimento. 8. ed. rev., atual. e ampl. São Paulo: Revista dos Tribunais, 2006. v. 1.

${ }^{10}$ GRECO FILHO, Vicente. Da intervenção de terceiros. São Paulo: Saraiva, 1991. 
De outro modo não poderia ser, uma vez que um dos principais objetivos da denunciação da lide é atender aos princípios da economia processual e da presteza na entrega da prestação jurisdicional. Ao se afastar desses objetivos, ensejando um alargamento da discussão acerca do objeto dos autos, a denunciação não deve ser prestigiada, conforme já decidido pelo Superior Tribunal de Justiça, STJ. ${ }^{11}$

O presente trabalho discute, com base em decisões jurisprudenciais, a pertinência da utilização do instituto da denunciação da lide em ações indenizatórias interpostas contra as pessoas jurídicas que atuam na prestação de serviços médicos.

2. A aplicabilidade do art. 70, III, do Código de Processo Civil, nas ações indenizatórias por prestação de serviços médicos

Dentro da realidade das ações judiciais que discutem a má-prática da Medicina, não raro os autores das demandas elegem para o pólo passivo somente as pessoas jurídicas que figuraram na prestação de serviços médicos objeto da ação judicial.

Desse modo, em muitos processos, nos quais se discute o mau resultado de um ato médico, figuram como réus a instituição hospitalar na qual o serviço médico foi prestado ou, ainda, o plano de saúde que custeou o tratamento. Os prestadores de serviços médicos podem figurar individualmente ou ainda como litisconsortes, de acordo com os critérios estabelecidos pela parte autora para fundamentar sua pretensão indenizatória.

O fato é que essas pessoas jurídicas, quando acionadas por fato originário da prática de um ato médico, muitas vezes recorrem ao instituto da denunciação da lide para ampliar o pólo passivo da demanda e, supostamente, antecipar o exercício do direito de regresso.

Porém, o que se pode extrair da análise de julgados emanados pelo Tribunal de Justiça de São Paulo, TJSP, e pelo STJ é a conclusão de que houve uma inadequada invocação do instituto da denunciação da lide em situações nas quais não seria admissível a intervenção de terceiros ou, ainda, que a denunciação da lide, em alguns casos, foi utilizada como mero pretexto para que o denunciante se esquivasse da responsabilidade que lhe cabe.

Em acórdão proferido pelo TJSP, foi realizado julgamento de ação na qual o hospital foi apontado como o responsável por seqüelas advindas ao recém-nascido após o parto. A instituição hospitalar tentou denunciar à lide o médico obstetra que realizou o

${ }_{11}$ Resp n. 49.418 (1994/0016525-0), Quarta Turma, Min. Rel. Sálvio de Figueiredo Teixeira, v.u., j. 14/06/1994, DJ 08/08/1994. 
parto. O Tribunal, no entanto, entendeu que o caso não se enquadrava em nenhuma das hipóteses obrigatórias de denunciação da lide e que, além disso, a ação fora interposta com fundamento no Código de Defesa do Consumidor, diploma legal que veda o instituto da denunciação da lide. ${ }^{12}$

Em outra decisão, da lavra do mesmo Tribunal, utilizou-se o argumento de que a ação indenizatória por ato médico foi interposta com base na responsabilidade objetiva do hospital, não ficando comprovado ter sido dado à autora o direito de escolha do médico que realizou o procedimento. ${ }^{13}$

O posicionamento contrário à admissibilidade da denunciação da lide foi identificado também em decisões do Superior Tribunal de Justiça. ${ }^{14}$

O STJ procurou destacar a inaplicabilidade da denunciação da lide nos casos mencionados, salientando o litisconsórcio facultativo entre médico e hospital e, também, a necessidade de se invocar fatos novos ao trazer o médico para o pólo passivo, o que poderia prejudicar a parte-autora.

Afigura-se totalmente prejudicial aos interesses do autor a discussão sobre a ocorrência dos elementos da culpa dentro da demanda paralela instaurada pela denunciação.

O ingresso do médico nos autos como denunciado vem trazer fundamento jurídico novo, situação não-admitida por parte da doutrina e da jurisprudência. ${ }^{15}$

A questão adquire especial relevância nos dias atuais, em que pode ser presenciado um considerável aumento no número de demandas contra médicos e hospitais, nas quais se pleiteia indenização por danos morais e materiais com base em questionamento por vícios na prestação de serviços médicos.

\footnotetext{
12 TJSP, $10^{\text {a }}$ Cam. Dir. Priv., A.I. n. 440.570-4/4, Rel. Galdino Toledo Júnior, v.u., j. 02/05/2006.

13 TJSP, $3^{\text {a }}$ Cam. Dir. Priv, A.I. n. 424.479-4/1, Rel. Waldemar Nogueira Filho, v.u., j. 21/02/2006. No mesmo sentido: TJSP, $3^{\mathrm{a}}$ Cam. Dir. Priv, A.I. n. 349.387-4/5, Rel. Carlos Roberto Gonçalves e TJSP, $10^{\mathrm{a}}$ Cam. Dir. Priv., A.I. n. 218.062-4, Rel. Paulo Dimas Mascaretti, v.u., j. 23/10/2001.

${ }^{14}$ STJ, REsp n. 35.496-0-SP(93.0015088-0), Primeira Turma, Rel. Min. Demócrito Reinaldo, v.u., j. 01/12/1993; Resp n. 167416 (1998/0018515-1), Terceira Turma, Min. Rel. Waldemar Zveiter, v.u., j. 22/02/2000, DJ 10/04/2000, p. 84; REsp n. 299.108-RJ (2001/0002565-0), Quarta Turma, Rel. p/ acórdão Min. César Asfor Rocha, por maioria, j. 05/06/2001; REsp n. 125.669-SP (1997/0021651-9), Quarta Turma, Rel. Min. Aldir Passarinho Junior, por maioria, j. 20/09/2001, DJU 04/02/2002, p. 365; Resp n. 323401-RJ (2001/0054485-6, Terceira Turma, Rel. Min. Carlos Alberto Menezes Direito, v.u., j. 22/10/2001, DJ 18/02/2002, p. 420; REsp n. 445.845-SP (2002/0080409-0), Rel. Min. Aldir Passarinho Júnior, v.u., j. 09/09/2003, DJ 13/10/2003; Resp n. 673258-RS (2004/0096734-5), Terceira Turma, Rel. Min. Ari Pargendler, j. 28/06/2006, DJ 04/09/2006, p. 262.

15 STJ, Resp n. 45040/SP (1994/0006626-0), Quarta Turma, Rel. Min. Barros Monteiro, v.u., j. 19/05/1998, DJ 14/09/1998.
} 
A denunciação da lide analisada à luz da relação médico/hospital ou médico/ plano de saúde frente ao paciente/familiar usuário do serviço médico acarreta óbices fáticos e jurídicos que merecem ser levados em consideração pelo julgador.

O primeiro deles é que a pessoa jurídica eleita pelo autor da demanda para figurar no pólo passivo busca amparo na figura da denunciação da lide não-somente para garantir o direito de regresso - mas, em muitos casos, para tentar eximir-se de responsabilidade pela reparação do dano objeto da demanda principal, transferindo-a ao médico litisdenunciado.

O Superior Tribunal de Justiça já decidiu pela impossibilidade da denunciação prosperar em situações nas quais o denunciante tenta isentar-se de responsabilidade pelo evento danoso, atribuindo-a a terceiro. ${ }^{16}$

Outro óbice que não pode ser desconsiderado é o fato de que, com o advento do Código de Defesa do Consumidor, tendo a prestação de serviços integrado o rol de situações tuteladas pelo referido diploma legislativo, as ações indenizatórias fundadas em erro médico passaram a ser interpostas e julgadas sob a égide das inovações trazidas pela legislação consumerista.

Estando a denunciação da lide formalmente vedada pelo Código de Defesa do Consumidor, o julgador tem um forte fundamento legal para rejeitar essa modalidade de intervenção de terceiros nos autos do processo.

Ademais, como foi frisado em um dos acórdãos proferidos pelo Tribunal de Justiça do Estado de São Paulo, o consumidor tem pleno direito de escolher contra quem demandar, devendo a questão de eventual direito de regresso ser decidida em ação autônoma. ${ }^{17}$

Não bastasse a vedação expressa do CDC, deve ser salientado, ainda, que a relação entre denunciante e denunciado, dentro da realidade de serviços médicos ora abordada, configura-se litisconsórcio facultativo.

Como bem frisado pelo relator do acórdão citado acima, "em ação indenizatória, o litisconsórcio é sempre facultativo, podendo o pleiteante ingressar em juízo contra um ou todos os responsáveis solidários, estando, assim, ausentes os pressupostos do art. 47 do Código de Processo Civil'.

Tendo o Código de Defesa do Consumidor estabelecido que o prestador de serviços, com exceção dos profissionais liberais, responde com base na responsabilidade

\footnotetext{
${ }^{16}$ Resp n. 121674/PR (1997/0014623-5), Terceira Turma, Rel. Min. Carlos Alberto Menezes Direito, v.u., j. 08/09/1997, DJ 01/12/1997, p. 62740.

17 TJSP, $10^{a}$ Cam. Dir. Priv., A.I. n. 440.570-4/4, Rel. Galdino Toledo Júnior, v.u., j. 02/05/2006.
} 
objetiva, tal fator poderá ser decisivo para o autor definir o pólo passivo de sua ação indenizatória.

Do ponto de vista de estratégia jurídica, poderá ser muito mais interessante litigar sob a égide das benesses trazidas pela legislação consumerista do que adentrar o arenoso território da discussão sobre a culpa do médico.

Não se pode ainda deixar de considerar o fato de que o consumidor de serviços médicos muitas vezes escolhe o profissional com base em uma relação préestabelecida com o convênio do qual é contratante.

Nessa hipótese a escolha é feita com base na confiança existente entre contratante/consumidor e contratado/convênio, decidindo o consumidor por um profissional referendado pelo convênio médico do qual é usuário.

Havendo um mau resultado cirúrgico ou uma insatisfação com o atendimento médico recebido, torna-se inquestionável o direito do consumidor de mover ação indenizatória em face do prestador de serviços médicos que, antes do médico profissional liberal, é o convênio intermediador dos serviços.

$\mathrm{O}$ mesmo se pode dizer dos casos em que o consumidor busca atendimento em um determinado hospital, por ser este o nosocômio de referência indicado pelo convênio médico, e lá é atendido pelo médico-de-plantão.

Nessas situações, igualmente corretas as decisões de impetrar a ação somente contra o convênio médico, somente contra o hospital ou contra hospital e convênio em litisconsórcio passivo.

Ainda que a legislação civil admita a denunciação da lide nas hipóteses nãoobrigatórias, os julgadores criaram certa reserva em relação à sua aceitação.

Aliada à questão da vedação legal contida no Código de Defesa do Consumidor, nos acórdãos analisados, os Tribunais não reconheceram prejuízo em se decidir sobre eventual direito de regresso em ação autônoma.

Talvez essa postura seja explicável pelo fato de que, vindo o médico profissional liberal integrar a lide, a discussão jurídica adquire outros contornos, tornandose muito mais complexa e obrigando a perquirição sobre a ocorrência dos elementos da culpa na prática do ato médico questionado.

A previsão legal contida no art. $14, \S 4^{\circ}$, do Código de Defesa do Consumidor, de que a responsabilidade dos profissionais liberais será apurada mediante a verificação de culpa, torna a instrução probatória mais morosa e complexa, acarretando uma nova discussão para a demanda já em curso. 
O alargamento da discussão, inicialmente delineada com base na questão da responsabilidade objetiva, pode ser prejudicial à parte autora, aumentando o grau de complexidade do objeto da demanda, posto que, além da discussão técnica acerca da existência de eventuais vícios na prestação de serviços médicos, há de se discutir também a natureza da relação entre denunciante e denunciado.

Mesmo o direito de regresso é questão que desafia a produção de provas acerca da relação jurídica existente entre médico e pessoa jurídica litisdenunciante. A suposta obrigação de indenizar por força de lei ou de contrato, estipulada no inciso III do art. 70 do CPC, pode tornar-se discutível frente às várias modalidades de contratação praticadas por empresas prestadoras de serviços médicos, muitas delas existentes apenas na forma verbal.

Ao relatar recurso especial discutindo a admissibilidade da denunciação da lide em ação movida contra hospital por erro médico, o ministro relator do STJ ponderou que: "a aplicação do referenciado dispositivo não se faz indistintamente, sob pena de ensejar a pulverização da responsabilidade, pela atribuição de responsabilidade indireta, a causar evidente e indesejável procrastinação do feito, em detrimento do direito da parte autora". 18

Não se pode esquecer, ainda, que o instituto admite a denunciação sucessiva e, em algumas situações, o denunciado se vê obrigado a exercer também a função de denunciante, dada a extensão da relação jurídica que se formou na cadeia de prestação dos serviços médicos.

Ademais, sendo deferida a denunciação, na demanda paralela que se estabelece entre instituição denunciante e o médico denunciado, ao invés de se aliarem para vencer a demanda principal, os litisdenunciados acabam por litigar entre si, discutindo a quem caberia a responsabilidade pela reparação do dano perquirido pelo autor da demanda.

Se houvesse fidelidade aos objetivos do instituto, o denunciado haveria de colocar-se em atitude processual semelhante a do réu denunciante, ao que Pontes de Miranda definiu como atitude afirmativa-negativa. ${ }^{19}$

A discussão jurídica que se estabelece entre pessoa jurídica denunciante e médico denunciado leva ao convencimento de que, na maioria dos casos em que se busca

\footnotetext{
18 REsp n. 445.845-SP (2002/000804409-0), Quarta Turma, Rel. Min. Aldir Passarinho Júnior, v.u., j. 09/09/2003, DJ 13/10/2003.

19 MIRANDA, Francisco Cavalcanti Pontes de. Comentários ao código de processo civil. 2. ed. Rio de Janeiro: Editora Revista Forense, 1958. t. II.
} 
amparo no instituto da denunciação da lide, não há uma adequação perfeita do fato à norma invocada.

Não se pode deixar de reconhecer que é interesse do médico responsável pelo fato, que é objeto de uma ação indenizatória, discutir e defender corretamente sua atuação. Porém, essa questão do direito de regresso vem sendo utilizada de forma distorcida por hospitais e empresas de saúde como forma de tentar eximir-se da responsabilidade perante o consumidor.

A figura da denunciação da lide tem sido utilizada na ausência de outra mais adequada, que permita ao réu denunciante afastar sua responsabilidade e indicar um terceiro como único responsável pelo fato que enseja o pedido indenizatório.

\section{Conclusão}

A primeira das premissas a ser destacada é o reconhecimento de que a prestação de serviços médicos constitui relação de consumo, portanto, imperam nas discussões jurídicas que a envolvem as regras estabelecidas pelo Código de Defesa do Consumidor.

A aceitação dessa premissa nos leva a uma segunda, na qual deve ser reconhecido o direito do consumidor de eleger o pólo passivo da ação indenizatória que tem por objeto eventual falha na prestação dos serviços médicos, não estando o autor obrigado a litigar contra quem não quer.

A utilização do instituto da denunciação da lide nessas demandas não raro é aventada pelo denunciante como uma tentativa de esquivar-se da responsabilidade que lhe é atribuída pelo autor da demanda.

O ingresso do médico nos autos na qualidade de denunciado pode significar o advento de um novo fundamento jurídico, o que acarretará prejuízo aos interesses do autor e violação ao princípio da economia processual.

Há de se concluir pelo não-cabimento da denunciação da lide nas ações judiciais em que se perquire indenização por suposto vício em procedimento médico, sem prejuízo de eventual ação autônoma a ser movida futuramente pelo réu denunciante em face do médico denunciado, na qual se poderá decidir com clareza e objetividade a natureza jurídica da relação estabelecida entre ambos.

São Paulo, 28 de maio de 2007. 
Referências

CHEIM JORGE, Flávio. Chamamento ao processo. 2. ed. rev. e atual. São Paulo: Revista dos Tribunais, 1999.

GONÇALVES, Aroldo Plínio. Da denunciação da lide. 3. ed. rev. e atual. Rio de Janeiro: Editora Forense, 1998.

GRECO FILHO, Vicente. Da intervenção de terceiros. São Paulo: Editora Saraiva, 1991. . Direito processual civil brasileiro. 9. ed. atual. São Paulo: Saraiva, 1994. v. 1.

MIRANDA, Francisco Cavalcanti Pontes de. Comentários ao código de processo civil. 2. ed. Rio de Janeiro: Forense, 1958. t. II.

NERY JUNIOR, Nelson; NERY, Rosa Maria de Andrade. Código de processo civil comentado e legislação extravagante: atualizado até 01 de março de 2006. 9. ed. rev., atual. e ampl. São Paulo: Revista dos Tribunais, 2006.

WAMBIER, Luiz Rodrigues (Coord.). Curso avançado de processo civil: teoria geral do processo e processo de conhecimento. 8. ed. rev., atual. e ampl. São Paulo: Revista dos Tribunais, 2006. 